\title{
Moeda e Acumulação de Capital: Keynes, Robertson e o Conceito de Poupança
}

\section{Money and Capital Accumulation: Keynes, Robertson and the Concept of Saving}

\author{
Sérgio Fornazier Meyrelles Filho* \\ Rogério Arthmar**
}

\begin{abstract}
Resumo: O presente artigo busca recuperar os elementos centrais das concepções sobre a poupança formuladas por Keynes e Robertson nas décadas de 1920 e 1930. A seção inicial descreve a parceria entre ambos os economistas ao início do período, bem como as suas respectivas teorias a respeito do comportamento dos diferentes tipos de poupança, particularmente as de natureza compulsória, ao longo dos ciclos de acumulação de capital. Em seguida, revisita-se o princípio da demanda efetiva e a teoria do multiplicador, conforme desenvolvidos na Teoria geral do emprego, do juro e da moeda, de modo a identificar os seus pontos de distanciamento relativamente à análise associada à doutrina da poupança forçada. Após, a atenção volta-se às críticas de Robertson ao mecanismo do multiplicador de renda. Finalizando, discute-se o contra-argumento de Keynes, o qual envolveu a modificação nos determinantes da demanda por moeda mediante a incorporação do conceito de meios financeiros em sua teoria do investimento. Na conclusão, procede-se a um sumário dos pontos em debate, apontando-se suas principais implicações teóricas.
\end{abstract}

Palavras-chave: Poupança. Investimento. Multiplicador. Fundos financeiros.

Abstract: This paper retrieves the central elements of Keynes's and Robertson's views about the concept of saving during the 1920s and 1930s. The first section covers the partnership between both economists at the beginning of the period, as well as their respective theories on the behavior of the multiple types of savings, particularly the ones of compulsory nature, along the cyclical process of capital accumulation. After that, the principle of effective demand and the multiplier theory, as developed in Keynes' General Theory, are examined in order to identify how these ideas moved away from the kind of analysis associated with the forced saving doctrine. Following this, the attention is focused on Robertson's criticisms of the income-multiplier mechanism. The last section discusses Keynes's counter argument, especially the adjustment he conducted in his theory of investment by incorporating the notion of finance into the liquidity demand function. The concluding remarks sum up the debate, pointing out its main theoretical repercussions.

* Doutor em Economia. Professor da Universidade Federal de Goiás (UFG) e do Programa de Pós-Graduação em Economia da Universidade Federal do Espírito Santo (UFES). E-mail: fornazier@ ufg.br

* $\quad$ Doutor em Economia. Professor do Programa de Pós-Graduação em Economia da Universidade Federal do Espírito Santo (UFES). Pesquisador $\mathrm{PQ} 2$ do $\mathrm{CNPq}$, instituição à qual o autor agradece o apoio. E-mail: rogerio.arthmar@ufes.br 
Keywords: Saving. Investment. Multiplier. Finance.

JEL Classification: B22; B26; B30.

\section{1 lntrodução}

Na Teoria geral do emprego, do juro e da moeda (1936, doravante Teoria geral), John Maynard Keynes promove ruptura irreversível com a escola clássica do pensamento econômico, representada, em sua essência, pela Lei de Say, pela teoria quantitativa da moeda e, no tocante às taxas de juros, pela teoria dos fundos de empréstimo (loanable funds theory), elaborada, entre outros, por Alfred Marshall. A nova abordagem da economia proposta por Keynes se assentava em dois pilares fundamentais. O primeiro consistia no princípio da demanda efetiva, conferindo às decisões de gasto dos agentes econômicos, em particular àquelas ligadas ao investimento, a primazia no tocante à determinação da dinâmica do produto e do emprego, em antítese à visão dominante de que toda a oferta geraria a sua própria demanda. O segundo pilar da nova economia keynesiana envolvia a concepção de moeda enquanto ativo capaz de afetar motivos e decisões, condição manifesta na necessidade de redefinição da taxa de juros enquanto fenômeno essencialmente monetário, determinado no âmbito de uma teoria da preferência pela liquidez. Nesse contexto, Keynes propunha, portanto, a superação da visão tradicional segundo a qual, em nível agregado, a poupança determinaria o investimento, sendo o equilíbrio entre ambas as variáveis promovido pela taxa de juros. De acordo com a perspectiva delineada na Teoria geral, a precedência em tal relação caberia ao investimento, porquanto a sua igualdade com a poupança passava a estar garantida pelas alterações no nível de renda, de acordo com a operação do multiplicador de gastos.

O impacto das ideias de Keynes se fez notar de forma marcante já nos anos seguintes após a publicação da Teoria geral. Parte importante do debate verificado no período, conforme atestam documentos e correspondências da época, teve lugar na própria Escola de Cambridge, sendo protagonizado por Keynes e seu antigo colaborador, Dennis Holme Robertson. A contenda centrava-se em torno de uma antiga ideia, originada no início do século anterior, recentemente revisitada e desenvolvida por Robertson no âmbito da análise dos ciclos econômicos, a chamada doutrina da poupança forçada. ${ }^{1}$

O presente ensaio busca recuperar os principais elementos do referido debate, situando suas origens no período anterior a 1936, quando a parceria entre os dois economistas atingiu o seu ponto culminante. Essa etapa inicial constitui o objeto da primeira seção. Em seguida, revisita-se o princípio da demanda efetiva e a teoria do multiplicador, conforme desenvolvidos na Teoria geral, de modo a

1 Para as origens do conceito na escola clássica, ver Corry (1962, p. 55-61) e Hayek (1932). 
identificar os seus pontos de distanciamento relativamente à análise do tipo poupança forçada. Após, a atenção volta-se às críticas de Robertson à noção do multiplicador de renda. Finalizando, apresenta-se o contra-argumento de Keynes, que o levaria a modificar sua função demanda por moeda.

\section{Antecedentes: Robertson e os Tipos de Poupança}

Em 1910, logo após iniciar a carreira acadêmica em Cambridge, Keynes trava contato com o jovem e promissor aspirante a economista Robertson. A relação entre mestre e pupilo gradualmente se transformaria em longa e intensa parceria cujos principais frutos seriam colhidos ao longo das décadas de 1920 e início de 1930 (PRESLEY, 1979, p. 75-84; SAMUELSON, 1963). Nesses anos, Keynes e Robertson trabalham arduamente no sentido de desenvolver suas respectivas teorias do ciclo econômico, integrando-as a uma análise rigorosa do comportamento da poupança e do investimento. De tal atividade e, em grande medida, da colaboração entre os dois estudiosos, nasceram A tract on monetary reform (1923) e A treatise on money (1930, doravante Treatise), redigidos por Keynes, assim como Money (1922) e Banking policy and the price level (1926, doravante Banking policy), assinados por Robertson. Embora nenhum desses livros tenha sido publicado sob dupla autoria, a intensa correspondência entre ambos os autores no período, registrada nos Collected writings of John Maynard Keynes (MOGGRIDGE, 1987a, 1987b) atesta a importância da parceria. Os documentos revelam, além disso, que o ápice da interação entre os dois economistas ocorreu durante a elaboração de Banking policy, no ano de 1925. Na ocasião, Robertson buscava analisar os aspectos monetários do ciclo econômico e, em especial, desenvolver a teoria da poupança forçada.

O assunto já havia sido tratado de forma embrionária em sua obra anterior, Money, quando foram descritos a estrutura e os efeitos da ação do sistema bancário. Numa economia com população e eficiência técnica estacionárias, argumenta Robertson, uma expansão dos empréstimos redundaria em demanda acrescida por bens e serviços e elevação geral nos preços, de modo que o público enfrentaria o dissabor de dividir a sua renda real com os beneficiários dos recursos bancários adicionais. Tratar-se-ia, nesse caso, da ocorrência de poupança compulsória. Interessante também é a possibilidade reversa contemplada no livro, de que um acréscimo na disposição a poupar por parte do público redundasse unicamente em retração na demanda e queda nos preços, permanecendo inalterado o consumo real sem implicar, portanto, sacrifício concreto por parte dos indivíduos parcimoniosos, configurando a assim chamada poupança abortiva (savings running to waste): 
Mas conseguiram esse objetivo [os poupadores] - e esse é o fato surpreendente - sem qualquer dos inconvenientes habituais da poupança; sem serem obrigados a se abster do consumo de qualquer produto ou serviço. Pois, como acima explicamos, os produtores e comerciantes terão deduzido os preços para poder dispor do mesmo volume de mercadorias e serviços de sempre. A austeridade do público foi desperdiçada, sem ter beneficiado a indústria ou o comércio em qualquer forma. (ROBERTSON, 1960, p. 77).

Robertson acreditava que embora os fatores monetários não fossem capazes de gerar flutuações cíclicas do produto de maneira isolada, poderiam afetar de forma considerável a amplitude de tais oscilações, de modo que a necessidade de uma análise rigorosa acerca das forças monetárias presentes ao longo dos ciclos se mostrava cada vez mais premente. Segundo a tipologia por ele adotada, um indivíduo estaria poupando (lacking) se, durante dado intervalo, consumisse menos que o valor do seu produto corrente. Então, imaginemos, por hipótese, a existência de apenas dois períodos de produção sucessivos. Considerando-se o fato de que a produção, por suposto, implica dispêndio de tempo, o produto resultante de um processo produtivo corrente estaria disponível aos indivíduos que dele participaram, direta ou indiretamente, apenas ao final do intervalo de produção, para ser, então, alocado entre consumo e poupança. A demanda em determinado período estaria definida, portanto, pela produção do período imediatamente anterior. Dessa forma, o volume de poupança (ou despoupança) corrente resultaria da diferença entre o volume de produção em dado momento e o consumo no momento seguinte, ou seja, $S_{t}=Y_{t-1}+C_{t}$.

Percebe-se, na equação, a introdução de importante elemento de retardo temporal (time-lag) que, conforme analisado adiante, teria importantes desdobramentos em relação à dinâmica do modelo de Robertson a partir da incorporação de outro tipo de defasagem, qual seja, aquela existente entre o reajuste de determinados rendimentos monetários, sobretudo salários, e a remarcação dos preços. Vejamos a questão mais de perto. No esquema teórico robertsoniano existiriam dois tipos principais de capital. O capital fixo consistiria no estoque de instrumentos de produção disponível à economia num determinado momento. Já o capital circulante estaria constituído por um conjunto de bens de consumo e matérias-primas, nos mais diversos estágios de produção, que permitiriam a continuidade do processo produtivo. A expansão do capital fixo da economia deveria se financiada por "poupança de longo prazo" ou, no léxico particular de Robertson, long lacking. De outra parte, permanecendo todos os demais fatores constantes, o valor do capital circulante necessário à produção estaria diretamente relacionado à duração do período produtivo. Sua provisão deveria ser garantida a partir da oferta de "poupança de curto prazo" ou short lacking. Nos termos de Robertson: "Long Lacking permite fornecer à sociedade [...] instrumentos de produção fixos e duráveis: Short 
Lacking destina-se a habilitar a sociedade a prosseguir com a produção - inclusive a produção de instrumentos duráveis" (ROBERTSON, 1932, p. 41).

Uma vez alcançado esse estágio da análise, cabe introduzir aqui o elemento central do modelo proposto em Banking policy e que nos leva diretamente à sua teoria da poupança forçada, qual seja, a distinção entre poupança voluntária, automática e induzida. De acordo com Robertson (1932, p. 47), o termo "poupança voluntária" (spontaneous lacking) identificaria o que normalmente era designado poupança no sentido marshalliano. Assim, a parcela dos recursos correntes de um indivíduo, em dado período, que ele optara livremente por não consumir e cuja magnitude dependeria, tudo o mais constante, de sua renda e da taxa de juros, configuraria uma poupança de tipo espontâneo. De modo reverso, caso o indivíduo consumisse deliberadamente mais do que o valor dos seus recursos correntes, ocorreria despoupança voluntária (spontaneous dis-lacking). Obviamente, a mesma lógica aplicar-se-ia no plano agregado, ou seja, em termos da economia como um todo. Todavia, esclarece Robertson, se por um lado seria correto sustentar que em uma situação de equilíbrio monetário o volume total de poupança disponível para fins de acumulação coincidiria com a poupança espontânea (spontaneous lacking), a mesma afirmação não poderia ser mantida em uma situação de desequilíbrio, quando os fluxos monetários estivessem sujeitos a flutuações. Em tal circunstância, seria necessário considerar não somente a poupança voluntária, mas também aquela de caráter forçado, a qual se apresentaria sob duas formas diferentes.

A primeira forma, denominada poupança automática, deveria ser analisada a partir do conceito de restrição automática (automatic stinting), o qual teria lugar quando um aumento no montante de dinheiro direcionado ao mercado de bens reduzisse o consumo efetivo de certas pessoas (ROBERTSON, 1932, p. 47). A ampliação no fluxo de dinheiro poderia ter origem na decisão de alguns indivíduos em reduzir seus encaixes monetários, realizando "desentesouramento" (dis-hoarding), ou então na criação de dinheiro novo, notadamente por meio do sistema de crédito. Em ambas as situações, segundo a lógica da teoria quantitativa da moeda, o dinheiro adicional em circulação provocaria elevação dos preços e garantiria aos seus novos detentores o acesso a uma parcela da produção que, caso contrário, resultaria consumida por outros indivíduos. Os prejudicados seriam todos os cidadãos com rendimentos nominais fixos, como, por exemplo, os assalariados.

$\mathrm{O}$ argumento pode ser resumido da seguinte forma: devido a um aumento na quantidade de moeda encaminhada ao mercado de bens, determinados indivíduos ver-se-iam obrigados, por força do sistema de preços, a consumir menos, situando o seu nível real de consumo em patamar inferior àquele que haviam planejado anteriormente. Além disso, se a queda no poder de compra da moeda contraísse também a despesa total de consumo dos indivíduos, tal recuo representaria 
poupança automática. O que sucederia, contudo, no caso oposto, na hipótese de uma redução do fluxo monetário direcionado ao mercado de bens? O evento, de acordo com Robertson, geraria uma situação em que o consumo real dos indivíduos poderia ser expandido em resposta ao corte nos preços dos bens correspondentes, fenômeno por ele denominado ampliação automática (automatic splashing), ou seja, o contrário da restrição automática. Caso a despesa efetiva de consumo dos indivíduos aumentasse de forma a superar o valor inicialmente planejado para tanto, ter-se-ia, então, "despoupança automática" (automatic dis-lacking).

Tabela 1 - Tipos de poupança segundo Robertson

\begin{tabular}{cccccccccccc}
\hline $\boldsymbol{t}$ & $\boldsymbol{Y}$ & $\boldsymbol{p}$ & $\boldsymbol{q}$ & $\boldsymbol{C}$ & $\boldsymbol{A}_{\boldsymbol{s}}$ & $\boldsymbol{L}_{\boldsymbol{s}}$ & $\boldsymbol{L}_{\boldsymbol{a}}$ & $\boldsymbol{L}_{\boldsymbol{i}}$ & $\boldsymbol{S}$ & $\boldsymbol{k} \boldsymbol{Y}$ & $\boldsymbol{k} \mathbf{Y} / \boldsymbol{p}$ \\
\hline 1 & 2.000 & 5,0 & 360 & 1.800 & 0,0 & 200 & 0 & 0 & 200 & 400 & 80 \\
2 & 2.000 & 5,2 & 346 & 1.800 & $-3,8$ & 200 & 0 & 0 & 200 & 400 & 77 \\
3 & 2.000 & 5,2 & 335 & 1.744 & $-3,8$ & 200 & 40 & 16 & 256 & 416 & 80 \\
4 & 2.000 & 4,8 & 375 & 1.800 & 4,1 & 200 & 0 & 0 & 200 & 400 & 83 \\
5 & 2.000 & 4,8 & 385 & 1.848 & 4,1 & 200 & -32 & -16 & 152 & 384 & 80 \\
\hline
\end{tabular}

Fonte: Elaboração própria a partir de Robertson (1932, p. 40-58).

Nota: $Y=$ renda monetária; $p=$ preço do bem de consumo; $q=$ quantidade adquirida do bem de consumo; $C=$ despesa de consumo; $A_{s}=-\pi /(1+\pi)=$ restrição automática (automatic stinting) ou ampliação automática (automatic splashing) em valor percentual, em que $\pi=$ taxa de inflação em relação a $p_{1} ; L_{s}=\alpha Y=$ poupança voluntária, $\alpha=0,1$ (spontaneous lacking); $L_{a}=$ poupança automática (automatic lacking); $L_{i}=$ poupança induzida (induced lacking); $S=L_{s}+L_{a}+L_{i}=$ poupança total; $k Y=0,2 Y=$ encaixe monetário médio; $k Y(q)=(k Y / p)=$ encaixe monetário real em bens de consumo [nível ótimo $(k Y)^{*}=80$ ]. Assumiu-se elasticidade-preço da demanda $e_{p}=-1,5$ para o artigo de consumo.

Em acréscimo, existiria ainda outro tipo de poupança forçada, denominada induzida (induced lacking) por Robertson. Suponhamos, inicialmente, que devido a um aumento na quantidade de moeda direcionada ao mercado de bens, o nível de preços tenha se elevado, e determinado grupo de indivíduos se veja submetido a um processo de poupança automática. Admitamos agora que esse reajuste nos preços tenha reduzido o valor dos seus estoques monetários, em termos reais, a nível inferior àquele por eles considerado ideal. Tais indivíduos procurariam, então, recompor o nível ótimo dos seus encaixes monetários retirando moeda de circulação por meio de certa redução em suas despesas de consumo. Na medida em que eles estivessem, dessa forma, consumindo menos do que o valor do seu produto corrente, ocorreria um processo de poupança induzida. No caso oposto, quando de uma contração da quantidade de moeda no mercado, a queda dos preços faria com que o valor real dos estoques monetários se situasse acima do valor considerado como apropriado, e as pessoas procurariam recompor esse nível 
ótimo, consumindo mais do que anteriormente, configurando, então, um processo de despoupança induzida (induced dis-lacking). Como se lê em Banking policy:

A Poupança Induzida [induced lacking] ocorre quando o mesmo processo que impõe a restrição automática [automatic stinting] sobre certas pessoas, ao reduzir o valor real de seus estoques de moeda, faz com que elas retenham dinheiro fora do mercado e se abstenham de consumir o valor integral de seu produto corrente a fim de elevar novamente o valor real de seus estoques de moeda ao nível que elas consideram apropriado. (ROBERTSON, 1932, p. 49, tradução nossa).

A Tabela 1 anterior ilustra os diversos conceitos de poupança propostos por Robertson para o caso de um indivíduo em uma economia simplificada na qual se dispõe de um único bem de consumo. No momento inicial $t=1$, para a renda pessoal $Y=2.000$ e consumo total $C_{1}=1.800$ do artigo correspondente com preço unitário $p_{1}=5$, perfazendo um total de $q_{1}=360$ unidades adquiridas, resulta poupança voluntária (spontaneous lacking) $L_{a 1}=200$. Considere, em $t=2$, a ocorrência de inflação de $4 \%$, de modo que o preço unitário do bem de consumo passe a $p_{2}=5,2$. Se a despesa de consumo, em termos nominais, permanece inalterada, o indivíduo sofre restrição automática (automatic stinting) igual a $A_{s 1}$ $=-3,8 \%$ na quantidade consumida, que se contrai para $q_{2}=346$, enquanto o encaixe monetário real declina de um patamar inicial ótimo $(k Y)_{1}=80$ para $(k Y)_{2}=$ 77 , de modo que a poupança total permanece inalterada. Se, em $t=3$, contudo, o indivíduo ajusta os seus gastos de consumo a fim de restabelecer seu encaixe monetário ideal, bem como em resposta à sua elasticidade-preço da demanda $e_{p}=-1,5$, então a despesa realizada com o bem em questão irá diminuir para $C_{3}$ $=1.744$. Essa redução no consumo deve-se à poupança automática (automatic lacking) $L_{a 3}=40$ e à poupança induzida (induced lacking) $L_{13}=16$, de sorte que a poupança total, agora, soma $S_{3}=256$. As situações descritas nos períodos $t=4 \mathrm{e}$ $t=5$ dizem respeito a uma deflação no preço do bem de consumo, com processos de ajustamento análogos, mas em sentido contrário. ${ }^{2} 3$

2 Seja a função poupança robertsoniana dada por $S=Y-C(Y, i, p, k Y / p)$, na qual $Y$ é a renda monetária, $i$ é a taxa de juros nominal, $p$ é o preço dos bens de consumo e $k$ é a proporção da renda mantida na forma de saldos inativos. Tem-se, então, para o diferencial total da poupança:

$$
d S=\left(1-\frac{\partial C}{\partial Y}\right) d Y-\left(\frac{\partial C}{\partial i}\right) d i-\left(\frac{\partial C}{\partial p}\right) d p-\left(\frac{k}{p}\right) d Y-\left(-\frac{k Y}{p^{2}}\right) d p-\left(\frac{\partial C}{d k}\right) d k
$$

primeiro e segundo termo da expressão à direita da equação indicam os efeitos da propensão a consumir e da taxa de juros sobre a poupança voluntária. O terceiro termo representa as variações na poupança automática, enquanto os três últimos termos mostram o impacto das modificações no encaixe monetário dos indivíduos. Os efeitos totais das variações em $Y, i, p$ e $k$ são positivos. A formulação matemática pouco convencional de Robertson em Banking policy é refeita, de maneira mais simples, por Bigg (1990).

3 Para abordagens alternativas a respeito dos tipos de poupança em Robertson, consultar Bridel (1987, p. 111-123), Presley (1979, p. 97-116), Mehta (1978, p. 109-117) e Wilson (1958). 


\section{Da Colaboração à Ruptura}

As ideias sobre a poupança descritas na seção anterior, como mencionado, adquiriram forma acabada em meados da década de 1920, período de notória e produtiva parceria intelectual entre Keynes e Robertson. Com base nesse fato, é interessante questionar: estaria Keynes, na época, em acordo com a teoria da poupança forçada? As evidências indicam que ele não apenas acreditava na validade dessa teoria como também se mostrou responsável, em certo grau, pelo seu desenvolvimento. Em versão preliminar do capítulo 3 do Treatise, escrito em novembro de 1924, Keynes, ao analisar os efeitos de uma expansão do crédito durante a fase ascendente do ciclo, inseriu a seguinte alusão à poupança forçada: "É verdade, como veremos adiante, que a alta dos preços pode acrescer o fluxo de poupança corrente ao impor um tributo sobre os consumidores e assalariados em favor dos produtores" (MOGGRIDGE, 1987a, p. 22, tradução nossa). Entre maio e novembro de 1925, Keynes e Robertson travaram intensas discussões relativas aos esboços de Banking policy, sobretudo em relação às teses apresentadas nos capítulos 5 e 6 do livro. O material ali desenvolvido constitui o cerne do argumento de Robertson e descreve de forma pormenorizada o mecanismo da poupança forçada. A despeito de certas diferenças iniciais, aos poucos os dois economistas parecem ter chegado a um denominador comum. Em carta a Robertson, datada de setembro daquele ano, Keynes afirmava: "Gosto desta última versão, embora Deus saiba como ela é concisa" (MOGGRIDGE, 1987a, p. 39, tradução nossa). Pouco tempo depois, em novembro, Keynes parecia satisfeito com o resultado alcançado por Robertson: "Penso que o seu capítulo v revisado é esplêndido - basicamente novo e importante. Acredito que esteja essencialmente correto e, finalmente, não tenho crítica substancial a fazer" (MOGGRIDGE, 1987a, p. 40, tradução nossa). Robertson, no capítulo introdutório de Banking policy, reconheceu explicitamente o papel desempenhado por Keynes no desenvolvimento das teorias apresentadas no livro:

Tive inúmeras discussões com Mr. J. M. Keynes a respeito do assunto dos capítulos V e VI e, tendo os reescrito tão drasticamente sob sua orientação, penso que nenhum de nós possa dizer quais idéias ali contidas são dele ou minhas. Gostaria, embora não o deva, de encontrar certas palavras que expressassem adequadamente minha dívida sem parecer comprometê-lo com opiniões que ele não compartilha. (ROBERTSON, 1932, p. 5, tradução nossa). 
No que se refere à teoria da poupança forçada, especificamente, é conhecido o fato de que o conceito de poupança induzida (induced lacking), introduzido por Robertson em Banking policy como uma inovação em relação à análise proposta em Money, foi a ele sugerido por Keynes em carta escrita em maio de 1925. Com efeito, ao analisar o impacto de um acréscimo no gasto público financiado por emissão monetária, com consequente repercussão nos preços, Keynes indicou que os encaixes monetários deveriam aumentar devido aos seguintes fatores: a) queda no valor real dos depósitos do público; b) redistribuição de renda em favor de indivíduos mais propensos ao entesouramento; e c) aumento na taxa de juros. Por outro lado, ele indicou ainda que a majoração dos preços poderia ter impacto negativo sobre os encaixes monetários em virtude de dois fatores: d) expectativas de aumento da inflação; e e) empobrecimento de determinados setores da sociedade, reduzindo a sua capacidade de entesourar (MOGGRIDGE, 1987a, p. 36-37). Robertson, em reconhecimento à contribuição do colega, registrou: "A Restrição Automática pertence a Mr. Keynes” (ROBERTSON, 1932, p. 50, tradução nossa).

Percebe-se que quando Banking policy veio a ser publicado, verificava-se total entendimento entre Keynes e Robertson no tocante à teoria da poupança forçada. "Essas duas mentes tinham considerável influência recíproca nessa época" (HARROD, 1982, p. 372, tradução nossa). ${ }^{4}$ O consenso parecia ainda existir em fins de 1929. Em agosto desse ano, nos rascunhos do que deveria ser o capítulo 23 do Treatise, Keynes fornecia evidência de acreditar na existência da poupança forçada. Afirmava, então, que se durante a fase expansiva do ciclo a demanda por investimentos superasse a oferta genuína (ou voluntária) de poupança, os bancos seriam acionados. A expansão do crédito, por meio da subsequente elevação do nível de preços, promoveria uma transferência de recursos reais no interior da comunidade, que estaria obrigada a restringir o seu consumo para que os empresários pudessem então expandir as suas atividades. Keynes dizia ainda que essa poupança forçada seria de dois tipos, os quais Robertson havia denominado de poupança automática e induzida. Ou, segundo o texto original,

A primeira forma [de inflação creditícia] é aquela que temos considerado em várias situações anteriores, a saber, mediante o aumento dos preços o crédito desvia o comando sobre a renda disponível que, de outra maneira, seria apropriada por aqueles previamente na posse de recursos monetários, para as mãos dos empreendedores que possuem bens recém-saídos do processo produtivo, aos quais este comando aparece como lucro extraordinário na conta de capital; os empreendedores encontram-se então em condição de colocar tais recursos à disposição de uma nova categoria de consumidores "produtivos". Mas não apenas aqueles detentores de rendas monetárias percebem que tem sua renda real diminuída; os possuidores de um estoque de dinheiro descobrem

4 Consultar também Presley (1979, p. 115) e Bridel (1987, p. 109-110). 
que tal estoque encontra-se agora em patamar inferior ao valor real pretérito e podem, portanto, serem induzidos a poupar numa escala maior do que fariam de outra maneira. (MOGGRIDGE, 1987a, p. 104-105, tradução nossa).

Para desapontamento de Robertson, ${ }^{5}$ porém, a versão final do Treatise, publicada em outubro de 1930, desconsiderava quase inteiramente a existência da poupança forçada. Keynes continuava acreditando que os montantes de poupança e de investimento poderiam ser temporariamente diferentes e, mais do que isso, sustentava que tal divergência constituiria a principal força geradora das flutuações cíclicas. Ele, no entanto, passara a utilizar novas definições de poupança e de investimento, apontando outras causas para a discrepância entre as duas variáveis e independentes da atuação do sistema bancário. O referido capítulo 23 desaparecera de todo, deixando poucos rastros. ${ }^{6}$ Além disso, as recomendações de política monetária adiantadas por Keynes eram claramente conflitantes com as ideias apresentadas em Banking policy. Em seu livro, Robertson defendera a tese de que durante a fase expansiva do ciclo a política monetária (ou bancária) deveria ser conduzida de forma a permitir a ampliação do crédito e a elevação dos preços em grau suficiente para garantir, via poupança forçada, o aumento do nível de atividade justificado pelas condições de utilidade e custos. "Em tais condições [fase expansiva], parece injustificado esperar que o sistema bancário assegure tanto a provisão adequada de capital circulante quanto a preservação da estabilidade de preços" (ROBERTSON, 1932, p. 72, tradução nossa). Esse tipo de flutuação seria, segundo ele, inevitável e, até certo ponto, necessária para o progresso econômico. Já Keynes, no Treatise, afirmava ser a estabilidade de preços o objetivo fundamental da política monetária o qual, como regra, jamais deveria ser sacrificado (KEYNES, 1935, p. 297).

Seja como for, não é possível afirmar que nesse estágio já houvesse sido verificado um total afastamento de Keynes relativamente à doutrina da poupança forçada. Na mesma obra, é possível ainda identificar determinadas passagens reminiscentes desse conceito, como a seguinte: "A inflação das mercadorias realmente aumenta os recursos disponíveis para novos investimentos e serve para acrescer o estoque de riqueza da sociedade" (KEYNES, 1935, p. 298, tradução nossa). O rompimento definitivo com a teoria robertsoniana, contudo, não tardaria a acontecer. Nos debates com Robertson, Ralph Hawtrey e Friedrich von Hayek, entre outros,

$5 \quad$ No prefácio da edição revisada de Banking policy, publicada em 1949, Robertson expressou claramente o seu desapontamento com o colega: "Embora Keynes devesse, naquele tempo [1926] ter compreendido e aquiescido com meu método passo a passo, é evidente que o mesmo jamais foi por ele absorvido; pois em seus dois sucessivos tratamentos do tema poupança-investimento ele o descartou completamente. Essa atitude, naturalmente, representou grande desapontamento para mim" (ROBERTSON apud BRIDEL, 1987, p. 111, tradução nossa).

Ver Keynes (1935, p. 293-299). 
após a publicação do Treatise, transcorridos entre 1931 e 1934 (MOGGRIDGE, 1987a, p. 201-336), Keynes tornaria cada vez mais evidente a sua busca por novos caminhos para a análise econômica. ${ }^{7}$ Nessa época, certa hostilidade de sua parte em relação ao conceito de poupança forçada já era visível, sobretudo no debate com Hayek, quando Keynes contestou as definições tradicionais de poupança voluntária e compulsória, cuja diferença resultaria da ação creditícia dos bancos na criação de poder de compra além daquele decorrente da abstinência espontânea dos indivíduos:

Minha análise é bem diferente disso, como deveria ser, pois em minha
forma de ver, poupança e investimento (como eu as defino) podem se
diferenciar sem qualquer distanciamento da condição de "neutralidade"
por parte do sistema bancário, como definida por Mr. Hayek, simples-
mente como resultado de alteração na taxa de poupança do público ou
na taxa de investimento dos empreendedores, não havendo qualquer
mecanismo de ajustamento automático no sistema econômico (como a
visão do Dr. Hayek sugere deva existir) para preservar a igualdade entre
as duas taxas, mantida inalterada a quantidade efetiva de moeda (MOG-
GRIDGE, 1987a, p. 251, tradução nossa).

Keynes, contudo, no âmbito do Treatise, ainda raciocinava com base nos ajustamentos entre oferta e demanda promovidos pelos preços, via lucros ou prejuízos extraordinários por parte dos produtores. Mas a exclusão deste último tipo de ganhos (ou perdas) da renda total, em que $S+Q=I$ ( $Q=$ lucros), permitiu a Keynes entrever que modificações na poupança poderiam acarretar mudanças no nível de renda. Em seus próprios termos: "[...] qualquer aumento (ou diminuição) na poupança 'voluntária' terá o efeito de diminuir (ou aumentar) a renda da comunidade em igual montante" (MOGGRIDGE, 1987a, p. 252, tradução nossa). A questão passaria a receber nova e radical abordagem em sua obra seguinte.

\section{A Poupança e o Multiplicador na Teoria Geral}

Com a publicação da Teoria geral, Keynes, por fim, adotaria postura extremamente crítica em relação à doutrina da poupança forçada. Na ocasião, afirmou categoricamente que tal fenômeno não possuiria sentido claro a menos que se adotasse a hipótese pouco realista de pleno emprego dos recursos produtivos

$7 \quad$ Como ressaltado por Presley (1979, p. 81), nesse período Keynes já se dedicava à preparação da Teoria Geral. Não obstante suas divergências em relação à versão final do Treatise, Keynes e Robertson continuavam a trabalhar juntos, muito embora, ao contrário do que acontecera anteriormente, Keynes recorresse agora com menor frequência ao seu antigo parceiro, interagindo mais intensamente com a jovem geração de economistas que compunha o chamado Cambridge Circus. Dentre esses novos colaboradores constavam Joan Robinson, Piero Sraffa, James Meade e Richard Kahn (DIMAND, 1988, p. 131-145). A parceria com Robertson chegaria ao fim em 1935 devido à sua discordância com as novas ideias de Keynes. 
(KEYNES, 1996, p. 104-106). Segundo Keynes, esse teria sido, de fato, o pressuposto originalmente utilizado pelos economistas clássicos no século XIX e resgatado pelos autores neoclássicos, incluindo-se Robertson, que se interessaram pela teoria. No tocante a esses últimos, observou ele: "De qualquer maneira, pelo que eu saiba nenhum esforço foi tentado pelos autores modernos, que se interessaram pela 'poupança forçada', para estender essa idéia a uma situação em que o emprego esteja aumentando" (KEYNES, 1996, p. 106). Poder-se-ia, então, contrapôs Keynes, adotar a seguinte definição: "A poupança forçada é o excedente da poupança real sobre o que se pouparia se houvesse pleno emprego numa situação de equilíbrio em longo prazo" (KEYNES, 1996, p. 105). Somente em tal condição, caracterizada pela indisponibilidade de recursos ociosos, a expansão adicional do investimento traria consigo elevação dos preços e redução do consumo, independentemente de eventual ampliação do crédito bancário. Aquém do pleno emprego, a variável de ajuste entre a poupança e o investimento seria a renda e não o nível de preços. Com base nisso, procurar-se-á entender mais detalhadamente o argumento de Keynes.

O ponto de partida da Teoria geral, como sabido, reside no princípio da demanda efetiva. Esse postulado teórico, em última instância, estabelecia que os volumes de emprego e renda da economia seriam determinados pelas decisões de despesa dos agentes econômicos (KEYNES 1996, p. 59-66). Keynes identificou dois tipos fundamentais de gasto no plano agregado da economia: em primeiro lugar, o consumo e, em segundo, os desembolsos realizados com vistas a ampliar o equipamento de capital da economia, o investimento. As rendas seriam geradas por empresários, produzindo bens e serviços em parte para o consumo e em parte para o investimento. Eles produziriam apenas aquela quantidade de mercadorias que projetassem capaz de ser efetivamente vendida com o lucro esperado. Assim, a demanda prospectiva por parte de consumidores e investidores definiria, em última análise, o que seria produzido e, portanto, a renda agregada. Dada, então, a propensão a consumir da comunidade, o nível de atividade econômica dependeria do montante do investimento. Nada garantiria, porém, que o valor dos desembolsos em novos bens de capital seria suficiente para promover a plena utilização dos fatores produtivos. Na verdade, advertia Keynes, o equilíbrio com pleno emprego seria pouco provável, constituindo-se apenas uma das inúmeras situações às quais estariam sujeitas as economias capitalistas.

Definido esse quadro, depara-se com duas questões centrais para a análise aqui desenvolvida. Primeiramente, que papel desempenhava a variável poupança na teoria de Keynes? Em segundo lugar, qual a relação existente entre a poupança e o investimento nesse arcabouço teórico? No que se refere ao primeiro questionamento, Keynes entendia que a poupança, definida como o excedente da renda sobre o consumo, nada mais seria do que uma variável reflexa, cujo valor final 
resultaria das decisões de gasto dos agentes econômicos, os verdadeiros determinantes da magnitude da renda agregada. A parcela dos rendimentos então gerados não utilizada para o consumo, por definição, constituiria a poupança agregada, cujo caráter subordinado no contexto maior da economia foi explicitado por Keynes na seguinte passagem:

A poupança, de fato, não passa de um simples resíduo. As decisões de consumir e as decisões de investir determinam, conjuntamente, os rendimentos [...]. Uma decisão de consumir ou não consumir está, certamente, ao alcance do indivíduo, o mesmo sucedendo com uma decisão de investir ou não investir. Os montantes da renda agregada e da poupança agregada são resultados da livre escolha dos indivíduos sobre se consumirão ou deixarão de consumir, sobre se farão ou não investimentos.

(KEYNES, 1996, p. 91-92).

A proposição acima nos leva também a uma resposta para nossa segunda questão. Considerando-se que a renda agregada estaria determinada pela adição dos gastos de consumo e de investimento, sendo a poupança o excedente da renda sobre o consumo, então a poupança e o investimento agregados deveriam resultar necessariamente iguais (LERNER, 1952a, p. 619-625). Assim, em contraste com a tese desenvolvida no Treatise, Keynes passou a afirmar, na Teoria geral, que eventual desigualdade entre as duas grandezas se afigurava evento impossível. Em suas próprias palavras: "Embora o montante da poupança agregada seja o resultado do comportamento coletivo dos consumidores individuais, e o montante do investimento, o resultado do comportamento coletivo dos empresários, esses dois montantes são necessariamente iguais". ${ }^{8} \mathrm{Ou}$, ainda, em outra passagem de teor similar: "A preponderância da idéia de que a poupança e o investimento, tomados em seu sentido literal, podem ser diferentes só se explica, no meu entender, por uma ilusão de ótica" (KEYNES, 1996, p. 106).

Cumpre observar que tal igualdade ocorreria à revelia do nível vigente da taxa de juros. Em outras palavras, ao contrário do que propunham Alfred Marshall e seus discípulos, a taxa de juros não seria o fator que, em última instância, asseguraria o equilíbrio entre poupança e investimento. Assim, os conceitos de taxa normal de juros ${ }^{9}$ (ou taxa quase-natural, como sugerido por Robertson) não teriam o menor sentido. A própria noção de uma curva de oferta de poupança

8 Essa afirmação de Keynes gerou uma série de críticas por parte de autores como Hawtrey e Bertil Ohlin. De acordo com os críticos, a abordagem utilizada por Keynes reduzia-se a uma mera tautologia, nada esclarecendo a respeito da relação de causalidade entre poupança e investimento. Uma avaliação de tais comentários se encontra em Bridel (1987, p. 160-161).

9 Conforme a definição do casal Marshall, "Quando as condições econômicas do país permanecem uniformes por longo período de tempo, a oferta de capital é de magnitude tal que a taxa de juros que pode ser obtida pelo seu uso é aquela requerida para ocasionar a disponibilidade da referida oferta; a taxa assim determinada é a taxa Normal" (MARSHALL; MARSHALL, 1994, p. 126, tradução nossa). 
independente da curva de demanda por investimentos, dizia Keynes, seria um erro lógico (MILGATE, 1982, p. 79-89; LERNER, 1952b, p. 634-654). Essa posição ficaria clara na correspondência com Roy Harrod a propósito dos esboços da Teoria geral. O primeiro argumentava que a discrepância entre poupança e investimento havia sido uma proposição rebuscada oriunda do Treatise, porquanto os neoclássicos sempre teriam defendido a igualdade entre as duas variáveis por conta das variações na taxa de juros (MOGGRIDGE, 1987a, p. 544-546). Keynes, em sua réplica, declarou que as curvas de oferta de poupança e de demanda por capital, expressando relação funcional com a taxa de juros, seriam inteiramente artificiais. $\mathrm{O}$ equilíbrio clássico no mercado monetário restaria indeterminado por se encontrar apoiado num raciocínio circular, somente adquirindo sentido mediante a aplicação do conceito de preferência pela liquidez. Não apenas a poupança e o investimento estariam invariavelmente nivelados como, ademais, se constituiriam inclusive na mesma coisa. Nas palavras de Keynes:

Imagino que o engano origine-se parcialmente no fato que, embora você tenha adotado no período recente a visão de que a poupança e o investimento são iguais, você ainda os pense como sendo coisas diferentes; enquanto eu os considero meramente como nomes diferentes para o mesmo fenômeno observado de perspectivas diversas [...]. Mas se a taxa de juros influencia a quantidade poupada na mesma direção da quantidade de investimento ou, ainda, se uma elevação na taxa de juros reduz a poupança, então a independência entre as duas coisas necessária à ação do juro como fator de equilíbrio cessa de existir. (MOGGRIDGE, 1987a, p. 551, tradução nossa).

No entendimento de Keynes, em situações aquém do pleno emprego a igualdade entre a poupança e o investimento estaria assegurada pelas variações na renda. Dada a propensão a consumir do público, o montante do investimento agregado determinaria a poupança agregada. Alterações no nível de investimento seriam automaticamente acompanhadas por variações, no mesmo sentido e de magnitude equivalente, do volume de poupança devido à operação do mecanismo multiplicador de gastos. Daí a fragilidade do esquema analítico clássico, que explicava a determinação da taxa de juros normal ou natural por meio de pretensa interação entre as supostas curvas de oferta de recursos livres (free capital, segundo Marshall) e a procura de fundos para investimento (KEYNES, 1996, p. 107-108). ${ }^{10}$

Já a teoria do multiplicador, desenvolvida por Keynes a partir do artigo original de Kahn (1931), postulava que, dada a propensão a consumir, existiria uma relação quantitativa definida entre a renda e o investimento realizado na economia

10 Para uma visão aprofundada da teoria marshalliana do equilíbrio monetário e dos ciclos comerciais, consultar Laidler (1999, p. 79-83), Bigg (1990), Bridel (1982) e Eshag (1964). 
durante certo período. ${ }^{11}{ }^{12}$ A medida desse efeito, o multiplicador, estaria diretamente relacionada à propensão marginal a consumir da comunidade. Em termos simplificados, pode-se escrever $\Delta Y=k \Delta I$, em que o multiplicador é dado por $k=$ $1 /(1-c)$, sendo $c$ a propensão marginal a consumir. Independentemente do seu valor, o multiplicador garantiria, em presença de recursos ociosos na economia, que a variação da renda agregada, decorrente de um aumento do investimento, seria suficiente para assegurar um acréscimo no volume de poupança equivalente ao investimento adicional.

Keynes acreditava que o processo de ajustamento da poupança ao investimento via multiplicador seria instantâneo e ocorreria sem alteração do nível de preços, pois havendo recursos desempregados, a oferta de bens e serviços resultaria perfeitamente elástica frente a uma ampliação da demanda. Portanto, diante da expansão do investimento, o produto e a renda assumiam o papel de variável de ajuste, em vez dos preços, como aceito comumente até então. Um aumento dos gastos em bens de capital geraria, por conta de seu efeito sobre o nível de renda, um acréscimo voluntário no volume de poupança exatamente suficiente para garantir o financiamento desses investimentos. Não haveria, por consequência, necessidade de interferência ativa do sistema bancário e, tampouco, espaço para qualquer tipo de poupança forçada. Apenas em uma situação hipotética de pleno emprego, afirmava Keynes, poder-se-ia conceber que uma ampliação do investimento conduziria a uma contração compulsória do consumo via sistema de preços. Mesmo assim, esse quadro não dependeria necessariamente da expansão do crédito. Dessa forma, Keynes desferia ataque frontal à teoria da poupança forçada que ele mesmo havia contribuído para desenvolver. Essa teoria, como vimos, ocupava lugar de destaque na análise de Robertson sobre as flutuações econômicas. Assim, diante da ofensiva keynesiana, parecia previsível que Robertson contra-atacasse, criticando duramente o conceito do multiplicador. Sua reação às posições de Keynes será tratada a seguir.

11 Para a colaboração entre Keynes e Kahn, ver Dimand (1988, p. 124-145) e Patinkin (1976, p. 54-82).

12 Embora o próprio Kahn não tivesse se dado conta, no momento, do alcance teórico de seus cálculos, elaborados em colaboração com James Meade: "Obviamente, o que tínhamos feito - mas que falhamos inteiramente em compreender - foi, por um método muito indireto, estabelecer a igualdade entre poupança e investimento, caso a poupança seja definida com base no senso comum em vez de nos termos do Treatise" (KAHN, 2011, p. 99, tradução nossa). Keynes, em maio de 1929, já ensaiara desenvolver uma série numérica semelhante em suas notas para um pronunciamento em favor do candidato liberal T. O. Jacobson (KENT, 2007). 


\section{Robertson, Keynes e o Debate sobre o Multiplicador}

Numa série de artigos na segunda metade dos anos de 1930, Robertson insistiria na tese de que a ideia do multiplicador padecia de grave deficiência, qual seja, a sua natureza eminentemente estática. Em carta a Keynes, ao final de 1936, ele observou: "O multiplicador somente se torna interessante quando, como sugerido por Hicks, ele adquire asas, ou seja, é utilizado para analisar um processo dinâmico" (MOGGRIDGE, 1987b, p. 97, tradução nossa). A visão keynesiana da economia, contestava Robertson, havia ignorado por completo o papel desempenhado pelo sistema monetário no financiamento do processo de acumulação de capital. Isso, por duas razões principais: a) por pressupor ajustamento instantâneo, via renda, da oferta voluntária de poupança ao volume de investimentos realizado na economia; e, além disso, b) por desconsiderar a existência de interação entre o multiplicador e o acelerador de investimentos.

Robertson não questionava o fato de que uma expansão dos investimentos levaria a um aumento gradativo do nível de renda da economia e que, ceteris paribus, a oferta voluntária de poupança seria progressivamente ampliada nesse processo. Entretanto, afirmava ele, existiria importante elemento de defasagem temporal inerente ao mecanismo multiplicador. Conforme discutido anteriormente, Robertson defendia a visão de que a produção implicaria dispêndio de tempo e, desse modo, não poderia ser expandida de forma instantânea. Nesse sentido, diante de um aumento da demanda por capital, levaria tempo para que fossem gerados acréscimos do produto e da renda suficientes para garantir o volume de poupança adequado a tal investimento. Robertson reconhecia que, uma vez omitido esse lapso de tempo, a questão estaria resolvida por si mesma: "[...] se estivermos dispostos a deixar de lado, como Mr. Kahn, o período de transição, podemos declarar que o problema do financiamento do processo de inversão se resolve por si mesmo" (ROBERTSON, 1956a, p. 128, tradução nossa). Porém, complementou Robertson, uma análise realista acerca dos fenômenos econômicos não poderia se resumir a um mero exercício de estática comparativa dessa natureza. 
Uma vez reconhecido o fato de que o processo de transição não poderia ser desconsiderado e que o multiplicador resultaria incapaz de promover o ajustamento instantâneo entre poupança e investimento, haveria, ainda, outro problema a considerar. Nada garantiria que a poupança voluntária adicional, gerada pela ação temporal do multiplicador, viesse a ser destinada a financiar o aumento original do investimento. Na opinião de Robertson, o multiplicador interagiria ao longo do tempo com o mecanismo complementar conhecido como acelerador de investimentos. ${ }^{13}$ Em síntese, uma eventual expansão nas inversões privadas estimularia um consumo adicional e esse acréscimo na demanda ocasionaria, de sua feita, expansão suplementar do investimento, tendo em vista o efeito positivo das vendas acrescidas sobre as perspectivas de lucro na economia. ${ }^{14}$ Robertson descreveu o processo da seguinte maneira: "[...] o gasto ampliado em artigos de consumo normalmente fornecerá um estímulo a uma inversão maior, assim como a inversão acrescida dará impulso a um consumo maior. O cachorro move o rabo e o rabo move o cachorro" (ROBERTSON, 1956a, p. 131, tradução nossa). O novo investimento ocasionado pela operação do acelerador competiria pela poupança gerada pelo investimento original. Esse movimento cumulativo, advertia Robertson, tenderia a agravar ainda mais o quadro de insuficiência de poupança voluntária no contexto de uma expansão econômica.

Tendo em conta os elementos descritos, Robertson levantou o seguinte problema: diante de uma escassez da poupança voluntária, de que forma seria possível financiar efetivamente uma acumulação de capital de maior intensidade? Em seu juízo, o questionamento necessariamente remeteria a análise à teoria da poupança forçada. A rigor, segundo Robertson, um surto nos investimentos seria financiado não apenas pela ação do multiplicador, mas também por intermédio de uma expansão do crédito bancário, assim como pelo desentesouramento de moeda. A inevitável expansão dos fundos de empréstimo causaria uma divergência entre a taxa natural e a taxa monetária de juros e, daí, a elevação do nível de preços. Durante o processo, teria lugar uma poupança forçada, mesmo em presença de recursos ociosos na economia. ${ }^{15}$ Por fim, a convergência da taxa de juros ao seu nível natural garantiria o equilíbrio entre a oferta e a demanda por poupança. Em tais condições, consistiria erro grave interpretar o multiplicador de um ponto de

13 Segundo Presley (1981, p. 180-181), o acelerador foi mencionado por Robertson pela primeira vez em A study on industrial fluctuations (obra originalmente publicada em 1915), sob a influência dos trabalhos do economista francês Albert Aftalion. No entanto, à época, ao contrário do que aconteceria na década de 1930, Robertson não demonstrara simpatia pela ideia.

14 Cf. Laidler (1999, p. 291-292).

15 Robertson, em verdade, não condicionara a existência de poupança forçada à prevalência de uma situação de pleno emprego dos recursos produtivos. A questão fundamental, para ele, residia na impossibilidade de que a produção reagisse instantaneamente a um aumento da demanda por bens e serviços. Em virtude dessa relativa inelasticidade da oferta é que os preços seriam elevados diante de uma expansão monetária, gerando transferência de recursos reais no interior da comunidade. 
vista exclusivamente estático e, por conta disso, julgar que a sua mera existência implicaria condenação liminar da doutrina da poupança forçada, tal como fizera Keynes. Em consequência, restaria equivocada igualmente a proposição de que a taxa de juros não desempenharia qualquer papel no processo de ajustamento entre a poupança e o investimento.

Em resposta à acusação de Robertson de que a participação do sistema bancário no processo de financiamento das inversões fora negligenciada na formulação conceitual do multiplicador, bem como às críticas dirigidas à sua teoria da preferência pela liquidez, Keynes, em junho de 1937, publicaria o artigo "Alternative theories of the rate of interest". Nele, veio a ser introduzido o conceito fundamental de meios financeiros (finance) (KEYNES, 1987c, 206-211). Antes de tudo, escreveu Keynes, seria essencial levar em conta a distinção entre o investimento planejado e o realizado. As decisões de investir, isto é, os investimentos planejados, implicariam uma demanda temporária por moeda a título de provisão financeira contra os gastos eventuais associados às novas atividades. Esses meios financeiros revelar-se-iam necessários, por assim dizer, para cobrir despesas contingentes ocorridas no intervalo entre o momento em que os investimentos foram planejados e aquele de sua efetiva realização. Em seus próprios termos: "Deve existir, portanto, uma técnica que preencha essa lacuna entre o instante em que a decisão de investir é tomada e o instante em que o investimento e poupança correspondente ocorrem de fato" (KEYNES, 1987c, p. 208, tradução nossa).

Keynes reconhecia, assim, a existência de uma fonte adicional de procura por moeda não vislumbrada na Teoria geral. Essa demanda para fins financeiros, da mesma forma que aquela motivada pelas transações, por precaução e para a especulação, poderia exercer influência sobre a taxa de juros, determinada agora pela demanda e oferta de moeda. De acordo com a sua nova visão sobre o assunto, a provisão de meios financeiros estaria garantida, principalmente, por intermédio dos bancos, podendo ser complementada pela emissão de ações. Considerando-se um ritmo estável de acumulação de capital na economia, essa provisão poderia ser realizada a partir de um fundo rotativo (revolving fund) de magnitude mais ou menos constante. À medida que determinado empresário refizesse sua demanda financeira, tendo em vista um novo projeto de investimento, ao mesmo tempo outro empresário estaria colocando fim à sua demanda particular em virtude da liquidação de um empréstimo pretérito, possibilitada pela efetivação do investimento que anteriormente planejara. ${ }^{16}$ Assim, o montante do fundo rotativo

16 Nesse ponto, Keynes se aproxima da assim denominada Real bills doctrine, de larga utilização nos debates monetários do século XIX na Inglaterra, segundo a qual os bancos apenas ampliariam o crédito para atender as necessidades efetivas do comércio, não podendo, portanto, ocorrer concessão excessiva de empréstimos. De forma similar, a Lei do Refluxo, do mesmo período, assegurava que as notas bancárias emitidas além das necessidades do público retornariam aos bancos na forma de depósitos (SKAGGS, 1991; CORRY, 1962, p. 53-55, 75-77). 
ou, noutras palavras, a parcela do estoque de moeda da economia comprometida com a demanda por meios financeiros, poderia ser considerado constante, conforme explicado por Keynes:

Se o investimento sucede a uma taxa estável, o financiamento (ou os compromissos de financiamento) requerido pode ser fornecido por um fundo rotativo de magnitude mais ou menos constante, um empreendedor tendo sua necessidade de recursos atendida para o propósito de investimento enquanto outro exaure a sua dívida pagando pelo investimento já realizado (KEYNES, 1987c, p. 209, tradução nossa).

Entretanto, uma aceleração na intensidade da acumulação de capital na economia, por hipótese, envolveria uma procura adicional de recursos monetários para provisão financeira que, claramente, não poderia ser satisfeita por meio exclusivo de um fundo rotativo de magnitude fixa. Assim ocorrendo, os bancos deveriam ampliar a oferta monetária da economia, pois, caso contrário, a insuficiência de meios financeiros se refletiria em uma elevação da taxa de juros. Diante de um aumento dos juros, a expansão dos investimentos pretendida pelos empresários seria bloqueada, ou seja, os investimentos efetivamente realizados ficariam aquém do inicialmente planejado:

A pressão para obter mais recursos do que o usual pode facilmente afetar a taxa de juros por meio de sua influência na procura por moeda; e a menos que o sistema bancário esteja preparado para aumentar a oferta de moeda, a falta de financiamento pode se revelar um obstáculo importante para uma determinada parcela de decisões de investimento que esteja em consideração no período (KEYNES, 1987c, p. 209, tradução nossa).

Dessa forma, Keynes admitia que o sistema bancário desempenharia papel importante no sentido de viabilizar a ampliação do investimento na economia, a qual poderia ter impacto direto na taxa de juros. Esse efeito, contudo, não comprometeria a validade da teoria da preferência pela liquidez. Isso porque a provisão de meios financeiros por intermédio dos bancos nada teria a ver com a oferta de poupança, diferentemente do que pressupunha Robertson. Esses recursos seriam tão somente, em última análise, registros contábeis que permitiriam aos empresários seguir adiante com segurança em seus planos de investimento. Nessa etapa inicial dos procedimentos, explicou Keynes, nenhuma poupança adicional haveria sido ainda realizada, assim como nenhum novo investimento: "No estágio financeiro das operações, não se tem qualquer poupança líquida por parte de alguém, assim como não há qualquer investimento líquido. 'Financiamento' e 'compromissos de financiamento' são apenas lançamentos de crédito e débito" (KEYNES, 1987c, p. 209, tradução nossa). Uma vez que o sistema bancário houvesse garantido a provisão adequada de meios financeiros, os investimentos planejados seriam, 
então, levados a efeito, e, em consequência, observar-se-ia automaticamente, via aumento da renda, a geração de oferta adicional de poupança equivalente a tais investimentos. Os preços permaneceriam inalterados e os novos recursos disponíveis para o financiamento do capital não apresentariam qualquer natureza compulsória. ${ }^{17}$ Keynes continuava, assim, a sustentar a validade da sua teoria do multiplicador, bem como a proposição de que a poupança e o investimento agregados apresentariam montantes necessariamente iguais. Na forma descrita por ele:

\begin{abstract}
Algumas pessoas entendem ser um paradoxo que, até o nível de pleno emprego, nenhuma montante de investimento, por maior que seja, possa exaurir e exceder a oferta de poupança, a qual sempre se manterá no mesmo ritmo. Se isso parece paradoxal, é porque se confunde com o fato de que uma pressão demasiada das decisões de investimento incompletas seja bem capaz de exaurir os financiamentos disponíveis [...]. Mas se o sistema bancário decide disponibilizar os recursos e os correspondentes investimentos projetados de fato se materializam, o nível apropriado de rendimentos será gerado e a partir do qual subsistirá uma quantidade de poupança exatamente suficiente para sustentar o novo investimento.

(KEYNES, 1987c, p. 210, tradução nossa).
\end{abstract}

Com relação a uma possível interação entre o multiplicador e o acelerador de investimentos, Keynes escreveu pouco. Ao discutir com Harrod, em abril de 1937, a possibilidade de existência de uma taxa "garantida" de crescimento da economia, calculada por meio da interação entre o multiplicador e a "relação", espécie de acelerador, Keynes comentou:

Até aqui, excluímos a possibilidade de mudanças nas expectativas. De fato, porém, a taxa de investimento não depende do consumo corrente, mas das expectativas [...]. Assim, a menos que as expectativas sejam de natureza constante, seria de se antecipar mudanças de curto-prazo na relação. (MOGGRIDGE, 1987b, p. 172, tradução nossa).

Dito de outro modo, a admissão do acelerador implicava o reconhecimento de um tipo de dependência funcional estável das inversões privadas em relação à renda que Keynes julgava incompatível com o caráter essencialmente frágil das projeções sobre o futuro. No artigo "The general theory of employment" (1937), esse aspecto da questão fica claro quando a procura pela liquidez e os rendimentos prospectivos dos negócios são apontados como fatores preponderantes na definição da taxa de juros e da escala de eficiência do capital:

17 Na verdade, a variável nível de preços não foi sequer mencionada por Keynes na ocasião. Porém, conforme exposto, ele defendia a tese de que aquém do pleno emprego, o produto e a renda, em vez dos preços, responderiam aos estímulos da demanda. Uma análise minuciosa da questão pode ser encontrada em Dimand (1988, p. 87-123). 
Não surpreende que o volume de investimento, assim determinado, deva flutuar de forma ampla de tempos em tempos. Pois ele depende de dois tipos de juízos sobre o futuro, nenhum dos quais repousa em fundações adequadas ou seguras - na propensão a entesourar e nas opiniões sobre o rendimento futuro dos ativos de capital. Não há tampouco qualquer razão pela qual as oscilações em um desses fatores tendam a neutralizar as oscilações no outro. (KEYNES, 1987b, p. 118, tradução nossa).

Robertson reagiu à explicação keynesiana sobre o elemento finance de duas formas principais. Na primeira, afirmou que a análise eliminava grave deficiência presente no argumento originalmente apresentado por Keynes na Teoria geral, ou seja, o não reconhecimento de que a demanda por investimentos poderia exercer influência direta sobre a taxa de juros (ROBERTSON, 1937, p. 432; ROBERTSON, 1938, p. 315-318; ROBERTSON, 1956b, p. 13-24). Segundo Robertson, com tal concessão, Keynes haveria se aproximado da ortodoxia marshalliana bem mais do que pensara. No artigo "Mr. Keynes and the rate of interest", de 1939, Robertson salientou: "[...] segundo creio, [Keynes] deu um salto para trás muito maior do que ele próprio imagina rumo à tese ortodoxa de que a escala da produtividade marginal dos fundos emprestáveis é o determinante principal da taxa de juros" (ROBERTSON, 1956b, p. 14, tradução nossa). Na segunda forma de reação, entretanto, ele argumentou categoricamente que Keynes havia sido deveras confuso em suas afirmações, particularmente ao obscurecer o papel desempenhado pela variável poupança no estabelecimento da taxa de juros: "Ao analisar o conceito de 'meios financeiros' do Senhor Keynes, eis que me distanciei em relação ao meu tema imediato. Sua fórmula parece propícia a levar à incerteza os que a utilizam no tocante ao papel desempenhado pela poupança na determinação da taxa de juros" (ROBERTSON, 1956b, p. 19, tradução nossa). ${ }^{18}$

Keynes, em contrapartida, descartou veementemente ter havido de sua parte qualquer reaproximação aos princípios clássicos. De acordo com ele, as dificuldades experimentadas por Robertson em compreender a análise dos meios financeiros originavam-se em sua incorrigível confusão entre o fundo rotativo de moeda e a oferta de poupança. Eventual congestão no mercado de capitais somente poderia ser aliviada por fatores capazes de reduzir a demanda ou aumentar a oferta de moeda. A poupança não teria poder algum em liberar dinheiro ou em restaurar a liquidez da economia. As necessidades de moeda durante o curso da produção estariam ligadas aos hábitos pessoais, às técnicas bancárias e às operações rotineiras do mundo dos negócios, conformando um conjunto de práticas normalmente conhecidas pelo termo velocidade de circulação da moeda. "O recurso financeiro ou o dinheiro, o qual se encontra imobilizado no intervalo entre o planejamento e a execução, é liberado no tempo devido após o seu pagamento

18 Ver também Robertson (1937, p. 432-433). 
oriundo de renda, seja ela poupada ou gasta" (KEYNES, 1987d, p. 233, tradução nossa). Inclusive, em sua resposta a Ohlin a respeito da relevância dos conceitos ex ante e ex post, Keynes admitiu haver deixado de incluir na demanda por moeda, circunscrita unicamente ao nível da renda real efetiva em curso, a procura por liquidez decorrente das atividades planejadas de despesa, a qual poderia ser até mais importante do que a anterior em razão do prazo mais demorado de recuperação dos empréstimos.

O fato de que a poupança ex post aumente em valor idêntico ao do investimento ex post em nada ajuda na situação. A elevação na escala planejada de atividades aumenta por inteiro, enquanto durar, a demanda por liquidez, independentemente da escala de poupança. O mesmo permanece verdadeiro caso a atividade planejada pelo empreendedor ou o gasto planejado pelo público seja direcionado ao investimento ou ao consumo. (MOGGRIDGE, 1987b, p. 221, tradução nossa).

Robertson jamais se mostrou receptivo aos argumentos de Keynes, permanecendo convencido da pertinência de suas críticas e, nesse sentido, de seus argumentos quanto à validade do conceito de poupança forçada (PRESLEY, 1979, p. 89-91). O seu apego à teoria econômica tradicional, confrontado com a força da revolução keynesiana, motivariam, em grande medida, o abandono de Cambridge por parte de Robertson em 1939 para lecionar na London School of Economics. Pouco depois, com a deflagração da Segunda Guerra Mundial, o debate entre ambos seria por fim interrompido. Eles voltariam a trabalhar juntos, como membros da delegação britânica, durante a Conferência Internacional de Bretton Woods, em 1944. Entretanto, não haveria tempo para uma retomada das controvérsias teóricas. Com o fim da guerra, Robertson retornou a Cambridge para assumir o posto de Arthur C. Pigou, então aposentado, como titular da cadeira de economia política. Keynes viria a falecer em 21 de abril de 1946. ${ }^{19}$

\section{Considerações Finais}

O conceito de poupança forçada desenvolvido por Robertson, assim como as demais definições correlatas introduzidas em Banking policy, apoiavam-se numa visão do sistema econômico no qual a produção sempre antecederia os elementos de despesa. Em tais condições, quando os gastos do período corrente dependem da renda auferida no período anterior, tem-se que o investimento a qualquer momento precisará ser precedido de produção não consumida correspondente. Mas como novas adições ao suprimento de bens compatíveis com as inversões privadas demandam tempo até a sua plena disponibilidade no mercado, e como o

19 Para a recente retomada do debate, ver Oreiro (2000). 
poder de compra pode ser afetado pelo sistema bancário, existiria, de um lado, a possibilidade de diferenças entre ambas as variáveis, caracterizando um desequilíbrio agregado, e de outro, a exigência de um conjunto de condições nas quais prevaleceria a igualdade entre poupança e investimento. De acordo com a tradição marshalliana esposada por Robertson, isso significava a definição de uma taxa normal ou natural de juros em relação à qual toda a poupança realizada seria de caráter voluntário e inteiramente convertida em novos investimentos. No caso de disparidade entre as duas magnitudes, estando fixadas as quantidades de bens disponíveis em curto prazo, os ajustamentos deveriam ocorrer mediante o sistema de preços, com reflexos inevitáveis sobre os demais tipos de poupança induzidas ou compulsórias.

Keynes, de sua parte, buscou superar essa abordagem do problema econômico que compartilhara com Robertson nos anos anteriores ao Treatise. Daí até o advento da Teoria geral, firma-se em sua mente uma nova forma de interpretação da economia agregada, caracterizada pela precedência causal das decisões de gasto ante as de produção, e pelo ajustamento, via renda, da poupança ao investimento efetivo. Nesse contexto, as duas últimas variáveis não mais apareciam como determinantes dos movimentos do sistema, mas, sim, como determinadas pela propensão a consumir, pela escala de eficiência marginal do investimento e pela taxa de juros, a qual resultaria da interação entre a procura pela liquidez e a oferta de moeda. Esse era o ponto fundamental da divergência de Keynes com Robertson e os demais autores neoclássicos, pois, segundo os mesmos, um aumento na poupança ou uma redução no investimento tenderiam a rebaixar a taxa de juros, restabelecendo o equilíbrio da economia. Mas se essas duas quantidades determinam o volume agregado de emprego em vez da taxa de juros, como descrito na Teoria geral, então as conclusões daí obtidas tornam-se totalmente distintas, pois uma redução do gasto passa a ser vista como prejudicial ao emprego, e não mais como fator benéfico ao mesmo.

A crítica de Robertson à hipótese de operação instantânea do multiplicador, ao se concentrar no caráter temporal dos processos econômicos e na importância do sistema monetário no tocante à dinâmica do investimento, mostrou, contudo, que tais elementos teóricos, ao tempo da Teoria geral, ainda não se apresentavam plenamente desenvolvidos. Com efeito, eles viriam a ser aprimorados nos escritos posteriores do próprio Keynes, por meio do componente finance, elaborado em resposta aos argumentos de Robertson, que, com sua obstinada ideia de poupança forçada, terminou por desempenhar papel contundente no processo de revisão da teoria keynesiana original. 


\section{Referências}

BIGG, R. J. Cambridge and the monetary theory of production. The collapse of Marshallian economics. New York: St. Martin Press, 1990.

BRIDEL, P. Cambridge monetary thought: the development of saving-investment analysis from Marshall to Keynes. New York: St. Martin's Press, 1987.

CORRY, B. Money, saving and investment in English economics 1800-1850. New York: St. Martin's Press, 1962.

DIMAND, R. W. The origins of the Keynesian Revolution: the development of Keynes' theory of employment and output. Stanford: Stanford University Press, 1988.

ESHAG, E. From Marshall to Keynes: an essay on the monetary theory of the Cambridge School. New York: Augustus Kelley, 1965.

HARROD, R. The life of John Maynard Keynes. New York: W. W. Norton, 1982.

HAYEK, F. A. A note on the development of the doctrine of "forced saving". The Quarterly Journal of Economics, v. 47, n. 1, p. 123-133, Nov. 1932.

KAHN, R. F. The making of Keynes' General Theory. Cambridge: Cambridge University Press, 2011. 198, June 1931.

KENT, R. J. A 1929 application of multiplier analysis by Keynes. History of Political Economy, v. 39, n. 3, p. 529-543, 2007.

KEYNES, J. M. A teoria geral do emprego, do juro e da moeda. São Paulo: Nova Cultural, 1996. Publicado originalmente em 1936.

. A treatise on money. New York: Harcourt, Brace and Company, 1935. Publicado originalmente em 1930.

. Alternative theories of the rate of interest. In: MOGGRIDGE, D. (Ed.). The collected writings of John Maynard Keynes: the General Theory and after: Part II- Defence and development, v. XIV. London: MacMillan Press, 1987c. p. 201-215. Texto publicado originalmente em 1937.

. Mr. Keynes "finance". In: MOGGRIDGE, D. (Ed.). The collected writings of John Maynard Keynes: the General Theory and after: part II- Defence and Development, v. XIV. London: MacMillan Press, 1987d. p. 229-233. Publicado originalmente em 1938.

. The general theory of employment.. In: MOGGRIDGE, D. (Ed.). The collected writings of John Maynard Keynes: the General Theory and after: Part II-Defence and development, v. XIV. London: Macmillan, 1987b. p. 109-123. Publicado originalmente em 1937. 
. The pure theory of money: a reply to Dr. Hayek. In: MOGGRIDGE, D. (Ed.). The collected writings of John Maynard Keynes: the General Theory and after: Part I- Preparation, v. XIII, London: Macmillan, 1987a. p. 243-256. Texto publicado originalmente em 1931.

LERNER, A. Alternative formulations of the theory of interest. In: HARRIS, S. (Ed.). The new economics: Keynes' influence on theory and public policy. New York: Alfred Knopf, 1952b. p. 634-654. Publicado originalmente em 1944.

. Saving equals investment. 1938. In: HARRIS, S. (Ed.). The new economics: Keynes' influence on theory and public policy. New York: Alfred Knopf, 1952a. p. 619-625.

MARSHALL, M. P.; MARSHALL, A. The economics of industry. Bristol: Thoemmes Press, 1994. Publicado originalmente em 1879.

MEHTA, G. The structure of the Keynesian Revolution. New York: St. Martin's Press, 1978.

MILGATE, M. Capital and employment: a study of Keynes's economics. London: Academic Press, 1982.

MOGGRIDGE, D. (Ed.). The collected writings of John Maynard Keynes: the General Theory and after: Part I - Preparation, v. XIII. London: MacMillan Press, 1987a.

. (Ed.). The collected writings of John Maynard Keynes: the General Theory and after:

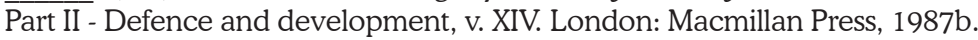

OREIRO, J. L. O debate entre Keynes e os clássicos sobre os determinantes da taxa de juros: uma grande perda de tempo? Revista de Economia Política, v. 20, n. 2, p. 95-119, 2000.

PATINKIN, D. Keynes' monetary thought: a study of its development. Durham: Duke University Press, 1976.

PRESLEY, J. R. Robertsonian economics: an examination of the work of Sir D.H. Robertson on industrial fluctuation. New York: Holmes $\mathcal{E}$ Meier, 1979.

ROBERTSON, D. H. A moeda. Rio de Janeiro: Zahar, 1960. (Manuais de Economia Cambridge). Publicado originalmente em 1922.

. Alternative theories of the rate of interest: rejoinder. Economic Journal, v. 47, p. 428436, Sept. 1937.

. Banking policy and the price level: an essay in the theory of the trade cycle. 1926. London: P.S. King E Son, 1932.

. La demanda efectiva y el multiplicador. In: . Ensayos sobre teoría monetaria. Madrid: Aguilar, 1956a. p. 124-132. Texto publicado originalmente em 1936.

. Mr. Keynes and finance. Economic Journal, v. 48, p. 314-318, June 1938.

. Mr. Keynes y el tipo de interés. In: . Ensayos sobre teoria monetaria. Madrid: Aguilar, 1956b. p. 3-43. Texto publicado originalmente em 1939. 
SAMUELSON, P. D. H. Robertson (1890-1963). The Quarterly Journal of Economics, v. 77, n. 4, p. 517-536, Nov. 1963.

SKAGGS, N. T. John Fullarton's law of reflux and Central Bank policy. History of Political Economy, v. 23, n. 3, p. 457-480, Fall 1991.

WILSON, T. Professor Robertson on effective demand and the trade cycle. The Economic Journal, v. 63, n. 251, p. 553-578, 1958.

Recebido em: 27/06/2012.

Aceito em: 30/09/2013. 